\title{
Editorial: Microbiotechnology Tools for Wastewater Cleanup and Organic Solids Reduction
}

\author{
Mayur B. Kurade ${ }^{1 *}$, Mukesh Kumar Awasthi ${ }^{2}$, Sanjay P. Govindwar ${ }^{1}$, Byong-Hun Jeon ${ }^{1 *}$ \\ and Dayanand Kalyani ${ }^{3}$ \\ 'Department of Earth Resources and Environmental Engineering, Hanyang University, Seoul, South Korea, ${ }^{2}$ College of \\ Natural Resources and Environment, Northwest A\&F University, Yangling, China, ${ }^{3}$ School of Industrial Biotechnology, Royal \\ Institute of Technology, Stockholm, Sweden
}

Keywords: emerging contaminants (ECs), wastewater treatment, phytoremediation, phycoremedation, nutrient removal, biodegradation, bioremediation

\section{Editorial on the Research Topic}

\section{Microbiotechnology Tools for Wastewater Cleanup and Organic Solids Reduction}

\section{OPEN ACCESS}

Edited by:

Sanket J. Joshi,

Sultan Qaboos University, Oman

Reviewed by:

Seung Gu Shin

Pohang University of Science and Technology, South Korea

*Correspondence:

Mayur B. Kurade mayurkurade@hanyang.ac.kr

Byong-Hun Jeon

bhjeon@hanyang.ac.kr

Specialty section:

This article was submitted to Microbiotechnology,

a section of the journal

Frontiers in Microbiology

Received: 20 November 2020 Accepted: 28 January 2021 Published: 18 February 2021

Citation: Kurade MB, Awasthi MK Govindwar SP, Jeon B-H and Kalyani D (2021) Editorial:

Microbiotechnology Tools for Wastewater Cleanup and Organic Solids Reduction

Front. Microbiol. 12:631506. doi: 10.3389/fmicb.2021.631506
Millions of people around the world lack access to safe water and suffer the consequences of unacceptable sanitary conditions due to contamination of water resources with various synthetic and geogenic compounds, which are being leached from agricultural, industrial, and domestic activities (Kurade et al., 2019; Xiong et al., 2021). The primary objective of a wastewater treatment plant is to reduce the concentrations of the pollutants to the level at which the discharge of the effluent will not adversely affect the environment or pose a health threat. Treatment of wastewater using bioremedial tools is an attractive approach because of their cost-effective and environmentally friendly properties. The modifications and improvements of existing biological treatment systems and/or addition of advanced technologies into wastewater treatment plants (WWTPs) is important to maximize the treatment efficiency. Along with the bacterial-mediated wastewater treatment, microalgae- and plant- based remediation is also of growing scientific interest (Rane et al., 2016; Huang et al., 2017; Vila-Costa et al., 2017). This Research Topic aims to gather the current advancements in microbial biotechnologies for wastewater treatment and biosolids reduction from urban and industrial wastewater. It includes eight original research articles that deal with related topics, ranging from novel methodology in quantifying the wastewater processes to the biologically facilitated removal and degradation of a diverse class of water pollutants.

The activated sludge process is a widely employed biological treatment of industrial and municipal wastewater. To achieve the highest treatment efficiency, it is important to monitor and maintain the optimum biomass concentration. Asgharnejad and Sarrafzadeh, proposed a cost-effective, high-throughput and errorless methodology of image processing and Red Green Blue (RGB) analysis for the quantification of activated sludge. Several essential parameters required for the deployment of such a method at large-scale industrial conditions are addressed.

The contamination of water resources with pharmaceutical contaminants has become a serious environmental problem in recent times. Xiong et al., utilized a green microalga, Scenedesmus obliquus, for the treatment of wastewater contaminated with doxylamine. Doxylamine exhibited negligible effect on S. obliquus and its biochemical characteristics, including pigments. As a result, S. obliquus exhibited the effective removal of doxylamine, chemical oxygen demand, and nutrients from the wastewater. Authors have shown the feasibility of using microalgae-based biotechnologies for wastewater treatment, but concluded that pilot-scale studies are needed for its implementation. 
Swine wastewater has detrimental effects on the water quality and aquatic ecosystem due to the presence of high concentrations of organic compounds, nutrients, heavy metals, and antibiotics. Therefore, Dan et al., investigated an intermittent cycle extended aeration system (ICEAS) for the removal of nutrients from anaerobically digested swine wastewater. Authors observed that the performance of the ICEAS was superior to conventional sequencing batch reactor technology in terms of nutrient removal, and the effluent quality was within the discharge standard, suggesting that ICEAS is a promising technology for wastewater treatment.

Water pollution created by colored wastewater is a serious issue as it leads to ecological disturbances and reduces the aesthetic value of water resources. It is immensely important to eliminate the xenobiotic compounds responsible for coloration before they are released into the environment. In this view, two original research articles in this article collection emphasized the application of bacterial-mediated remediation of two different kinds of colored wastewaters. Amin et al., improved the decolorization of a model, textile azo dye, Direct Red 81, under microaerophilic conditions by optimizing the nutritional and environmental parameters through statistical models. They explored the metabolic pathway and the active involvement of laccase and azoreductase in dye degradation and confirmed that the retrieved products were non-toxic. The contribution of Abdulsalam et al., focused on the decolorization of palm oil mill effluent using bacterial treatment. The treatment of palm oil mill effluent has been a challenge due to its intense brownish color due to excessive concentrations of tannins, melanoidin, and lignin compounds. Authors optimized the influential parameters of decolorization, including inoculum size, initial color concentration, and treatment time, using Response Surface Methodology.

The contribution of Thongpitak et al. outlined the treatment of a herbicide- paraquat contaminated waters using biologically synthesized manganese oxide considering its widespread contamination throughout the globe in soil and water, including rivers and surface waters, and its further accumulation in the food chain. The manganese oxide synthesized from microalga, Pediastrum duplex, performed Fenton-like reactions to deliver $50 \%$ degradation of paraquat within three days. It indicates that biosynthesized manganese oxide is an environmentally friendly alternative catalyst that can be effectively applied in wastewater treatment systems.

Phenol is a ubiquitous pollutant that is frequently observed in wastewater. Biological treatment of phenol-containing wastewater is an effective approach, however the toxicity of phenol on microorganisms hinders the process efficiency. Wang et al. explored the phenol tolerance mechanism of Candida tropicalis through transcriptomic analysis and showed that $C$. tropicalis prevented cell damage through improvement of cell wall resistance, maintenance of intracellular protein homeostasis, high-fidelity DNA replication, and organelle integrity. The outcomes of this study would help in the genetic modification of yeast for improving their efficiency of phenol degradation.

The utilization of Dendrobium plants for the phytoremediation of wastewater are highlighted due to their cost-effectivity and ecological advantages. Dendrobium nobile is the only plant that can produce the natural bioactive compound dendrobine, which has potential medical significance. The article by Sarsaiya et al., determined the presence of an endophytic fungal strain in D. nobile, and evaluated the production of endophyte and dendrobine using the molecular method and analytical characterization, respectively. The potential dendrobine producer strain in D. nobile was identified to be Trichoderma longibrachiatum, which exhibited strong bactericidal activity against common pathogens, indicating its potential in microbiotechnology fields.

With this Research Topic, we presented some newly developed techniques to deal with pollutants in wastewaters with a consideration of a broad readership with interest in the bioremediation of wastewater. Although the provided technologies are very attractive in terms of their efficiency, further in-depth investigations are needed to implement these technologies at an engineered scale. The inclusion of the existing research gaps and recommendations for future research in this Research Topic will ensure a productive progression toward a bright future of bioremediation.

\section{AUTHOR CONTRIBUTIONS}

All the authors of this editorial article have made a significant, direct and intellectual contribution to the work, and approved it for publication.

\section{FUNDING}

The theme of this Research Topic is based on the research projects received from the National Research Foundation of Korea (NRF), Ministry of Education, Science, and Technology (MEST) of the South Korean government (NRFNo. 2019R1I1A1A01063318 and No. 2019R1F1A1064379).

\section{ACKNOWLEDGMENTS}

This Research Topic was initiated to update the current progress of research in the field of bioremediation of waste. There is a total of eight manuscripts accepted for publication in this Research Topic that were contributed by 52 authors residing in several countries including Sweden, Malaysia, India, China, Netherlands, Iran, Nigeria, Vietnam, and Thailand. We would like to gratefully acknowledge all the research contributors for their invaluable work to this topic and encouraging the scientific community across the globe to become more involved in this research area. The editors would like to extend their gratitude toward the expert reviewers for their precious time given for the respected criticism meant to improve the quality and standards of the manuscripts. 


\section{REFERENCES}

Huang, X., Zheng, J. L., Liu, C. X., Liu, L., Liu, Y. H., Fan, H. Y., et al. (2017). Performance and bacterial community dynamics of vertical flow constructed wetlands during the treatment of antibiotics-enriched swine wastewater. Chem. Eng. J. 316, 727-735. doi: 10.1016/j.cej.2017.02.029

Kurade, M. B., Xiong, J. Q., Govindwar, S. P., Roh, H. S., Saratale, G. D., Jeon, B. H., et al. (2019). Uptake and biodegradation of emerging contaminant sulfamethoxazole from aqueous phase using Ipomoea aquatica. Chemosphere 225, 696-704. doi: 10.1016/j. chemosphere.2019.03.086

Rane, N. R., Patil, S. M., Chandanshive, V. V., Kadam, S. K., Khandare, R. V., Jadhav, J. P., et al. (2016). Ipomoea hederifolia rooted soil bed and Ipomoea aquatica rhizofiltration coupled phytoreactors for efficient treatment of textile wastewater. Water Res. 96, 1-11. doi: 10.1016/j. watres.2016.03.029

Vila-Costa, M., Gioia, R., Acena, J., Perez, S., Casamayor, E. O., and Dachs, J. (2017). Degradation of sulfonamides as a microbial resistance mechanism. Water Res. 115, 309-317. doi: 10.1016/j. watres.2017.03.007
Xiong, J. Q., Cui, P., Ru, S., Govindwar, S. P., Kurade, M. B., Jang, M., et al. (2021). Unravelling metabolism and microbial community of a phytobed co-planted with Typha angustifolia and Ipomoea aquatica for biodegradation of doxylamine from wastewater. J. Hazard. Mat. 401:123404. doi: $10.1016 /$ j. jhazmat.2020.123404

Conflict of Interest: The authors declare that the research was conducted in the absence of any commercial or financial relationships that could be construed as a potential conflict of interest.

Copyright () 2021 Kurade, Awasthi, Govindwar, Jeon and Kalyani. This is an openaccess article distributed under the terms of the Creative Commons Attribution License (CC BY). The use, distribution or reproduction in other forums is permitted, provided the original author(s) and the copyright owner(s) are credited and that the original publication in this journal is cited, in accordance with accepted academic practice. No use, distribution or reproduction is permitted which does not comply with these terms. 